\title{
Selective proteinuria in diabetic nephropathy in the rat is associated with a relative decrease in glomerular basement membrane heparan sulphate
}

\author{
J. van den Born ${ }^{1}$, A. A. van Kraats' ${ }^{1}$, M. A. H. Bakker ${ }^{1}$, K. J. M. Assmann ${ }^{2}$, L. P. W. J. van den Heuvel ${ }^{3}$, J.H. Veerkamp ${ }^{4}$, \\ J.H.M.Berden ${ }^{1}$ \\ ${ }^{1}$ Department of Nephrology, University Hospital St. Radboud, Nijmegen, The Netherlands \\ ${ }^{2}$ Department of Pathology, University Hospital St. Radboud, Nijmegen, The Netherlands \\ ${ }^{3}$ Department of Pediatrics, University Hospital St. Radboud, Nijmegen, The Netherlands \\ ${ }^{4}$ Department of Biochemistry, University of Nymegen, Nijmegen, The Netherlands
}

Summary In the present study we investigated whether glomerular hyperfiltration and albuminuria in streptozotocin-induced diabetic nephropathy in male Wistar-Münich rats are associated with changes in the heparan sulphate content of the glomerular basement membrane. Rats with a diabetes mellitus duration of 8 months, treated with low doses of insulin, showed a significant increase in glomerular filtration rate $(p<0.01)$ and effective renal plasma flow $(p<0.05)$, without alterations in filtration fraction or mean arterial blood pressure. Diabetic rats developed progressive albuminuria (at 7 months, diabetic rats (D): $42 \pm 13$ vs control rats (C): $0.5 \pm 0.2 \mathrm{mg} /$ $24 \mathrm{~h}, p<0.002)$ and a decrease of the selectivity index (clearance IgG/clearance albumin) of the proteinuria (at 7 months, D: $0.20 \pm 0.04$ vs C: $0.39 \pm 0.17$, $p<0.05$ ), suggesting loss of glomerular basement membrane charge. Light- and electron microscopy demonstrated a moderate increase of mesangial matrix and thickening of the glomerular basement membrane in the diabetic rats. Immunohistochemically an increase of laminin, collagen III and IV staining was observed in the mesangium and in the glomerular basement membrane, without alterations in glomerular basement membrane staining of heparan sulphate proteoglycan core protein or heparan sulphate. Glomerular basement membrane heparan sulphate content, quantitated in individual glomerular extracts by a new inhibition ELISA using a specific anti-glomerular basement membrane heparan sulphate monoclonal antibody (JM403), was not altered (median (range) D: 314 (152-941) vs C: 262 (244467) ng heparan sulphate/mg glomerulus). However, the amount of glomerular 4-hydroxyproline, as a measure for collagen content, was significantly increased (D: 1665 (712-2014) vs C: 672 (515$1208) \mathrm{ng} / \mathrm{mg}$ glomerulus, $p<0.01$ ). Consequently, a significant decrease of the heparan sulphate/4-hydroxyproline ratio (D: $0.21(0.14-1.16)$ vs $C: 0.39$ $(0.30-0.47), p<0.05)$ was found. In summary, we demonstrate that in streptozotocin-diabetic rats glomerular hyperfiltration and a progressive, selective proteinuria are associated with a relative decrease of glomerular basement membrane heparan sulphate. Functionally, a diminished heparan sulphate-associated charge density within the glomerular basement membrane might explain the selective proteinuria in the diabetic rats. [Diabetologia (1995) 38: 161-172]

Key words Glomerular basement membrane, heparan sulphate, collagen, glomerular filtration rate, albuminuria.
Received: 23 May 1994

and in revised form: 30 August 1994

Corresponding author: Dr. J. van den Born, Department of Nephrology, University Hospital St. Radboud, P. O. Box 9101, NL-6500 HB Nijmegen, The Netherlands
Abbreviations: BW, Body weight; ERPF, effective renal plasma flow; GAG, glycosaminoglycan; GBM, glomerular basement membrane; GFR, glomerular filtration rate; HS, heparan sulphate; HSPG, heparan sulphate proteoglycan; IDDM, insulin-dependent diabetes mellitus; STZ, streptozotocin. 
Heparan sulphate (HS) is the anionic glycosaminoglycan side chain of heparan sulphate proteoglycan (HSPG), the major proteoglycan present in the glomerular basement membrane (GBM) [1, 2]. Strong evidence indicates that this proteoglycan plays an important role in the maintenance of the charge-selective permeability properties of the glomerular capillary wall by electrostatic repulsion of anionic plasma proteins, especially albumin. This is clearly demonstrated by studies eliminating the presence or charge of GBM HS by heparitinase perfusion of the kidneys [3], intrarenal or intravenous injection of cationic probes [4-7] or antibodies against HS [8], all leading to an increased permeability of the GBM for albumin.

Diabetic nephropathy ultimately develops in 30 $40 \%$ of patients suffering from insulin-dependent diabetes mellitus (IDDM). Since diabetic nephropathy is initially characterized by microalbuminuria $[9,10]$, the significance of GBM HSPG for its development has been analysed in several studies. Moreover, the altered selectivity index of the proteinuria in patients with "incipient" diabetic nephropathy [11-14] suggested a decreased charge-dependent permeability of the GBM. Studies in humans revealed a relatively decreased content of HS and HSPG within the GBM of kidneys from IDDM patients [15-17]. A recent study using the cationic probe cuprolinic blue demonstrated a reduction of HS-associated anionic sites within the GBM, which was inversely correlated with the degree of albuminuria [18]. We found a decreased staining for HS in the GBM in kidney biopsies from diabetic patients, which correlated with the fractional protein excretion, whereas the GBM staining for the core protein of HSPG was unaltered $[19,20]$. Others, however, found a decreased GBM staining for the core protein of HSPG in diabetic kidneys $[21,22]$. Because of the limitations of the study of human material, investigations were also performed in experimental models of diabetic nephropathy. Most of these studies have been done on the streptozotocin (STZ)-induced diabetes model in the rat. Biochemical quantitation of HS in the GBM, in glomeruli or in renal cortex revealed a decreased [23-26] or unaltered [27, 28] HS content in rats with STZ-induced diabetic nephropathy. Others studied HS synthesis in GBM or glomeruli by in vivo ${ }^{35} \mathrm{~S}$-sulphate incorporation, which revealed either a decreased $[25,26,29]$ or normal $[30,31]$ synthesis of HS. Studies using ex vivo (isolated perfused kidney) or in vitro (short-term culture of glomeruli) ${ }^{35} \mathrm{~S}$-sulphate incorporation suggest a decreased HS synthesis $[32,33]$, although this was not been found by all investigators [30]. A clear interpretation of these results is hampered by the use of different rat strains, differences in diabetes duration, the absence or incomplete description of the development of a progressive diabetic nephropathy, and most importantly by the use of different techniques to evaluate the HS content, which are not specific for HS. A disadvantage of the incorporation studies is related to the rather indirect method used to identify the individual GAGs by either glycosaminoglycan-degrading enzymes, or nitrous acid treatment. In addition, one should realize that the rate of HS synthesis yields no information about the actual glomerular HS content, and that the proteoglycan synthesis of isolated glomeruli in tissue culture is very different from that in vivo [34].

Aside from structural GBM alterations, STZ-diabetic nephropathy is also characterized by an increased glomerular filtration rate (GFR) and an increased glomerular capillary pressure [35]. The significance of these altered renal haemodynamics is clearly demonstrated by intervention studies intended to prevent these haemodynamic changes, by reducing protein intake or by inhibition of the angiotensin-converting enzyme, which lead to a prevention or retardation of the progression of DNP [3638]. It is possible, therefore, that structural alterations in the glomerular capillary wall might be related to the changes in renal haemodynamics. Recently, we described a monoclonal antibody (mAb) against GBM HS [8]. Using this $\mathrm{mAb}$, we developed a sensitive inhibition ELISA, that enables us to specifically quantitate GBM HS in glomerular extracts of individual rats. This method circumvents laborious biochemical purification procedures, which have the disadvantage of considerable loss of HS during the procedure. Furthermore, based on the exclusive specificity of the mAb JM-403 for GBM-associated $\mathrm{HS}$, the assay is not influenced by the contamination of HS derived from resident glomerular cells, which represents $80 \%$ of glomerular HS [2]. Also, this method does not need the differentiation of HS from other GBM-associated GAGs by GAG-degrading enzymes. In the present study we used this specific HS quantitation technique to investigate whether changes in GFR and urinary protein excretion are associated with changes in GBM HS content in the STZ-induced diabetic nephropathy in the rat.

\section{Materials and methods}

Induction of diabetes and insulin treatment. Diabetes was induced in 15 overnight-fasted male Wistar-Münich rats (Jackson Laboratory, Bar Harbor, Me., USA) of $150 \mathrm{~g}$ body weight (BW) by intravenous injection of $55 \mathrm{mg} \mathrm{STZ/kg} \mathrm{BW}$, freshly prepared in $0.1 \mathrm{~mol} / 1$ citrate buffer ( $\mathrm{pH} 4.5), 25 \mathrm{mg} / \mathrm{ml}$. Animals were treated three times a week (Monday, Wednesday, Friday at 17.00 hours) with a low dose (1.2 IU) of bovine insulin (Ultralente; Novo, Copenhagen, Denmark) to maintain blood glucose levels around $25 \mathrm{mmol} / \mathrm{l}$. Time-and and age-matched rats $(n=5)$ that did not receive STZ served as controls. In two pilot experiments (see Results) the influence of insulin therapy was investigated. 
Longitudinal study during 8 months. Diabetic $(n=15)$ and control $(n=5)$ rats were followed for 8 months. Every 6 weeks animals were placed in metabolic cages to determine the urine production $(\mathrm{ml} / 24 \mathrm{~h})$, and the albumin and $\operatorname{IgG}$ excretion $(\mathrm{mg} / 24 \mathrm{~h})$. Urinary and serum albumin concentrations were determined by rocket immuno-electrophoresis according to Laurell [39] using goat anti-rat albumin and rat albumin as a standard (both from Nordic, Tilburg, The Netherlands). Urinary and serum $\operatorname{IgG}$ concentrations were determined in a capture ELISA as described [8], using rat $\mathrm{IgG}, 2-2000 \mathrm{ng} / \mathrm{ml}$ as a standard (Nordic). From these values the selectivity index of the proteinuria (clearance $\mathrm{IgG} /$ clearance albumin) was calculated. BW was determined every week, and blood glucose every month by Haemo-Glukotest 1-44R (Boehringer, Mannheim, Germany). Every 6 weeks GFR was calculated from the plasma disappearance rate of ${ }^{51} \mathrm{Cr}$-EDTA according to Provoost et al. [40], based on a single, timed $(60 \mathrm{~min})$ blood sample after a single i.v. injection of ${ }^{51} \mathrm{Cr}$-EDTA. The distribution volume of this tracer could be influenced by the disease state. However, in a short-term (2-7 weeks) STZ-diabetes study in the rat this alteration was negligible [41].

Renal clearance studies. Eight months after induction of diabetes, renal haemodynamics (effective renal plasma flow (ERPF) and GFR) were measured in 13 diabetic and 5 control rats ( 2 diabetic rats died just before these measurements) and thereafter kidneys were removed for histology and biochemical analysis. To this end rats were anaesthetized by Inactin (Byk Gulden, Konstanz, Germany) (control rats, $140 \mathrm{mg} / \mathrm{kg}$ BW; diabetic rats, $110 \mathrm{mg} / \mathrm{kg} \mathrm{BW}$ ) and placed on a heated pad which maintained rectal body temperature between 37 and $38^{\circ} \mathrm{C}$. The left femoral artery was cannulated for continuous measurement of arterial blood pressure and blood sampling. Tracheotomy was performed. Determination of renal function was done by a single intravenous injection of $0.2 \mathrm{ml}$ saline containing a cocktail of $2 \mu \mathrm{Ci}^{125} \mathrm{I}$-hippuran (to measure ERPF) and $10 \mu \mathrm{Ci}{ }^{51} \mathrm{Cr}$-EDTA (to measure the GFR). Blood samples were taken 5, 10, 20, 30, 40 and 60 min after injection. ERPF and GFR were calculated by the disappearance rate of both tracers from the circulation according to van Lambalgen et al. [42] with minor modifications. GFR values calculated by this method (based on six blood samples) correlate well according to the method of Passing and Bablok [43] with the GFR values obtained by calculation based on only the 60 -min blood sample as described above $\left(r^{2}=0.94\right.$ for diabetic rats and $r^{2}=0.99$ for control rats), although the one blood sample calculation method yielded somewhat lower GFR values in both control and diabetic animals. All clearance studies were performed $16 \mathrm{~h}$ after insulin administration the evening before.

Renal histology. After the clearance study, kidneys were removed, decapsulated and weighed. Small pieces of renal tissue were snap-frozen in liquid nitrogen for immunofluorescence, or immersed in paraformaldehyde-lysine-periodate fix* ative for electron microscopy or in Bouin's fixative for light microscopy (PAS and methenamine silver staining). Paraformaldehyde-lysine-periodate fixed renal tissue from eight diabetic and five control rats, was processed for electron microscopy. From each rat, three glomeruli were examined and 35 photographs of cross-sectioned GBM loops with a final magnification of $20,000 \times$ were taken per animal. GBM width was calculated with the aid of a VIDAS computerized image processor (Kontron Inc., München, Germany), and was derived from GBM area divided by GBM length. The GBM length was obtained by measuring the lengths of the lines delineating both sides of the GBM from epithelium and endothelium divided by two. Indirect immunofluorescence was performed on $2-\mu \mathrm{m}$ cryostat sections of the rat kidneys as described previously [8] using the following antibodies: goat anti-human GBM HSPG core protein [44], diluted 1:200; mouse anti-GBM HS mAb JM-403 [8], 1:500; rabbit anti-rat L2-laminin, 1:500; goat anti-collagen III (Sanbio, Uden, The Netherlands); and affinity purified goat anti-collagen IV ( $\alpha 1 / \alpha 2$; Southern Biotechnology Associates, Birmingham, Ala., USA), 1:200. As secondary antibodies we used FITC-labelled rabbit anti-goat IgG (Dako, Glostrup, Denmark), 1:500; FITC-labelled goat anti-mouse IgM (Fc) (Nordic), 1:100 and FITC-labelled goat anti-rabbit IgG (Kallestad, Chaska, Minn., USA), 1:500. In control experiments the FITC-labelled secondary antibodies were applied to the sections without prior primary antibody incubation.

Direct immunofluorescence was performed using FITC-labelled affinity purified goat anti-rat IgG (heavy and light chain; Jackson, West Grove, Pa, USA), 1:50; FITC-labelled rabbit anti-rat C3 (Nordic), 1:75; and FITC-labelled rabbit anti-human fibrin (Dako), 1:400. Sections were examined on a Zeiss Axioskop microscope equipped for fluorescence microscopy.

Determination of glomerular HS and 4-hydroxyproline content. Glomeruli from individual rats were isolated from renal tissue (1.5 kidney/rat) by the differential sieving technique according to Meezan et al. [45] using 150, 105 and 53 mesh sieves. The glomeruli remaining on the 53 mesh sieve were harvested with a purity of more than $90 \%$. Glomeruli were counted, weighed after centrifugation and after a 30-s sonication on ice (using a Soniprep 150, amplitude at 10 (one third of maximal power) ) extracted overnight at $4^{\circ} \mathrm{C}$ in $50 \mathrm{mmol} / 1$ sodium acetate buffer (pH 5.8) containing $4 \mathrm{~mol} / 1$ guanidine $\mathrm{HCl}$, $10 \mathrm{mmol} / \mathrm{l}$ EDTA and $1 \mathrm{mmol} / \mathrm{l}$ PMSF (100 $\mu \mathrm{l}$ extraction buffer/25 mg wet weight glomeruli). After centrifugation, the supernatant was taken for GBM HS determination and the remaining pellet was used to measure the 4-hydroxyproline content (representative for collagen) according to Berg [46].

GBM HS concentrations were determined in an inhibitionELISA, using mAb JM-403, directed against rat GBM HS [8]. Polystyrene flat-bottom microtitre plates (Nunc maxisorp; Gibco, Breda, The Netherlands) were coated overnight at room temperature with $50 \mu \mathrm{g} \mathrm{HS} / \mathrm{ml}$ (Seikagaku, Tokyo, Japan), $100 \mu 1 /$ well in phosphate buffered saline (PBS). After washing with PBS containing $0.05 \%$ Tween-20 (PBS-T), plates were blocked for $2 \mathrm{~h}$ at room temperature by PBS containing $1 \%$ gelatin, $120 \mu \mathrm{l} / \mathrm{well}$. Thereafter, the plates were washed and glomerular extracts, in a dilution range from 1:250 to 1:4000 in PBS-T and pre-incubated for $2 \mathrm{~h}$ with a 1:50000 dilution in PBS-T of JM-403, were transferred to ELISA plates and incubated for $1 \mathrm{~h}$ at room temperature. After washing, a 1:1000 dilution in PBS-T of peroxidase labelled affinity purified goat anti-mouse IgM (Fc) (Southern Biotechnology) was added to the plates, $100 \mu \mathrm{l} / \mathrm{well}$ and incubated for $1 \mathrm{~h}$ at room temperature. Thereafter the plates were washed and $100 \mu \mathrm{l}$ substrate solution/well were added. The freshly prepared substrate solution contained $75 \mu \mathrm{g}$ 3,3,5,5 tetramethylbenzidine (Sigma, St. Louis, Mo., USA) and $1 \mu \mathrm{l} 30 \% \mathrm{H}_{2} \mathrm{O}_{2} / \mathrm{ml} 0.1 \mathrm{~mol} / \mathrm{l}$ sodium acetate buffer ( $\mathrm{pH} 5.5)$. Reaction was stopped after $30 \mathrm{~min}$ with $2 \mathrm{~mol} / 1 \mathrm{H}_{2} \mathrm{SO}_{4}$ and absorption was measured at $450 \mathrm{~nm}$ using a Titertek multiscan. Bovine kidney HS (Seikagaku), 2$2000 \mathrm{ng} / \mathrm{ml}$ was used as standard. Percentage inhibition was calculated as $[1-(\mathrm{A} 450+$ inhibitor/A450 - inhibitor) $] \times 100 \%$. From the $50 \%$ inhibition value the glomerular HS content was calculated, compared to the standard curve. The intraand inter-assay coefficients of variation were $15.8 \%$ and $20.3 \%$, respectively. 
Table 1. Influence of 15 weeks insulin therapy on blood glucose, GFR and albuminuria in STZ diabetes in rats (means \pm SD or median values and range)

\begin{tabular}{|c|c|c|c|c|c|}
\hline & \multicolumn{2}{|l|}{ Experiment 1} & \multicolumn{3}{|l|}{ Experiment 2} \\
\hline & \multirow{2}{*}{$\begin{array}{l}\text { Diabetic rats } \\
\text { No insulin } \\
(n=11)\end{array}$} & \multirow{2}{*}{$\begin{array}{l}\text { Control rats } \\
\text { No insulin } \\
(n=8)\end{array}$} & \multicolumn{2}{|l|}{ Diabetic rats } & \multirow{2}{*}{$\begin{array}{l}\text { Control rats } \\
\text { No insulin } \\
(n=7)\end{array}$} \\
\hline & & & $\begin{array}{l}\text { Low insulin } \\
(n=4)\end{array}$ & $\begin{array}{l}\text { High insulin } \\
(n=4)\end{array}$ & \\
\hline Blood glucose $(\mathrm{mmol} / \mathrm{l})$ & $26.6 \pm 1.4^{\mathrm{a}}$ & $4.5 \pm 0.4$ & $21.1 \pm 1.3^{b, c}$ & $8.2 \pm 2.2$ & $5.2 \pm 0.3$ \\
\hline $\operatorname{GFR}(\mathrm{ml} / \mathrm{min})$ & $2.65 \pm 0.31$ & $2.44 \pm 0.28$ & $3.65 \pm 0.32^{b}$ & $3.16 \pm 0.45$ & $2.82 \pm 0.16$ \\
\hline Albuminuria $(\mathrm{mg} / 24 \mathrm{~h})^{\mathrm{e}}$ & $1.3(0.5-6.0)^{\mathrm{a}}$ & $0.4(0.3-0.6)$ & $4.6(1.4-14.5)^{\mathrm{b}, \mathrm{c}}$ & $0.4(0.3-0.6)^{\mathrm{d}}$ & $0.9(0.7-1.2)$ \\
\hline
\end{tabular}

${ }^{a}$ Diabetic vs control $p<0.001 ;{ }^{\mathrm{b}}$ low insulin vs control $p<0.01 ;{ }^{\mathrm{c}}$ low insulin vs high insulin $p<0.05 ;{ }^{\mathrm{d}}$ high insulin vs control $p<0.05 ;{ }^{\mathrm{e}}$ median value and range

\section{Statistical analysis}

For statistical analysis the Wilcoxon's test was used. Probability values $p<0.05$ were regarded as significant. Values are expressed either as means $\pm \mathrm{SD}$ or as medians and range if not normally distributed.

\section{Results}

Influence of insulin regimen of GFR and albuminuria. In two 15-week pilot experiments, we investigated which insulin regimen should be chosen to induce development of diabetic nephropathy. From Table 1, experiment 1 , it becomes clear that diabetic rats without insulin therapy demonstrate high blood glucose levels, while the GFR was not significantly different from controls and albuminuria was significantly higher than controls but considerably lower than animals treated with a low dose insulin (experiment 2). Treatment with low doses of insulin (mean $1.2 \mathrm{IU} /$ day) resulted in only a slight reduction of the blood glucose levels, but in a clear increase of the GFR and a much higher degree of albuminuria (Table 1, experiment 2 compared to experiment 1). An optimal metabolic control (high insulin in Table 1; mean $3.2 \mathrm{IU}$ insulin/ day) almost completely prevented these alterations, GFR was normal and albuminuria was even significantly lower than that in control rats. These results underline the importance of a low-insulin regimen to study hyperfiltration-related events in the STZ diabetes model in the rat.

Longitudinal study during 8 months of diabetes. Diabetic $(n=15)$ and control rats $(n=5)$ were followed for a period of 8 months for morning blood glucose, $\mathrm{BW}$, GFR, urine production and albuminuria (Fig.1). Diabetic rats showed significantly increased blood glucose levels, fluctuating around $25 \mathrm{mmol} / \mathrm{l}$, whereas the control rats remained at a constant blood level of $5 \mathrm{mmol} / \mathrm{l}$ (Fig. $1 \mathrm{~A}$ ). The diabetic animals gained significantly less weight compared to their litter mates (Fig.1B). Whereas the control rats reached about $350 \mathrm{~g} \mathrm{BW}$ at 32 weeks, the diabetic rats remained at a maximal $\mathrm{BW}$ of around $230 \mathrm{~g}$ from 18 weeks onwards. GFR was measured five times during the observation period. Figure $1 \mathrm{C}$ clearly demonstrates that at each time point the GFR in the diabetic rats was significantly higher compared to the values found in the control rats. With time, the GFR increased in both the control and diabetic rats due to an increase in BW [40]. For that reason we corrected the GFR for BW as shown in Figure 1D, which shows that this corrected GFR was stable during the study period. Furthermore, these results clearly indicate glomerular hyperfiltration directly after the onset of diabetes. As can be seen in Figure 1E, diabetic rats had a significantly higher diuresis than the control rats. At the same time, diabetic rats developed a progressive albuminuria rising to $42 \mathrm{mg} / 24 \mathrm{~h}$ at 29 weeks (Fig. 1F), whereas the control rats demonstrated a constant basal urinary albumin excretion ranging from $0.2-0.5 \mathrm{mg} / 24 \mathrm{~h}$. To investigate possible alterations in the charge-dependent permeability of the glomerular capillary wall, we calculated the selectivity index of the proteinuria (clearance of $\mathrm{IgG}$ divided by the clearance of albumin) at 16,22 , and 29 weeks after diabetes induction. The results demonstrate a decreasing selectivity index in the diabetic rats in course of the disease. This index is significantly different from the control rats at week 29 (Fig. 2). These latter results suggest a progressive disturbance in the charge-dependent permeability in diabetic rats, possibly resulting from an increasing loss of negative charge from the glomerular capillary wall. The data indicate the development of a progressive, selective albuminuria in association with a glomerular hyperfiltration, which is already present soon after induction of diabetes.

Renal clearance studies after 8 months of diabetes. After 8 months of diabetes renal haemodynamics were studied in more detail including estimation of the ERPF. The results in Table 2 show a significant increase in GFR and ERPF, that becomes even more significant after correction for BW. At the same time no differences were seen in mean arterial pressure and filtration fraction between the two groups. Kid- 

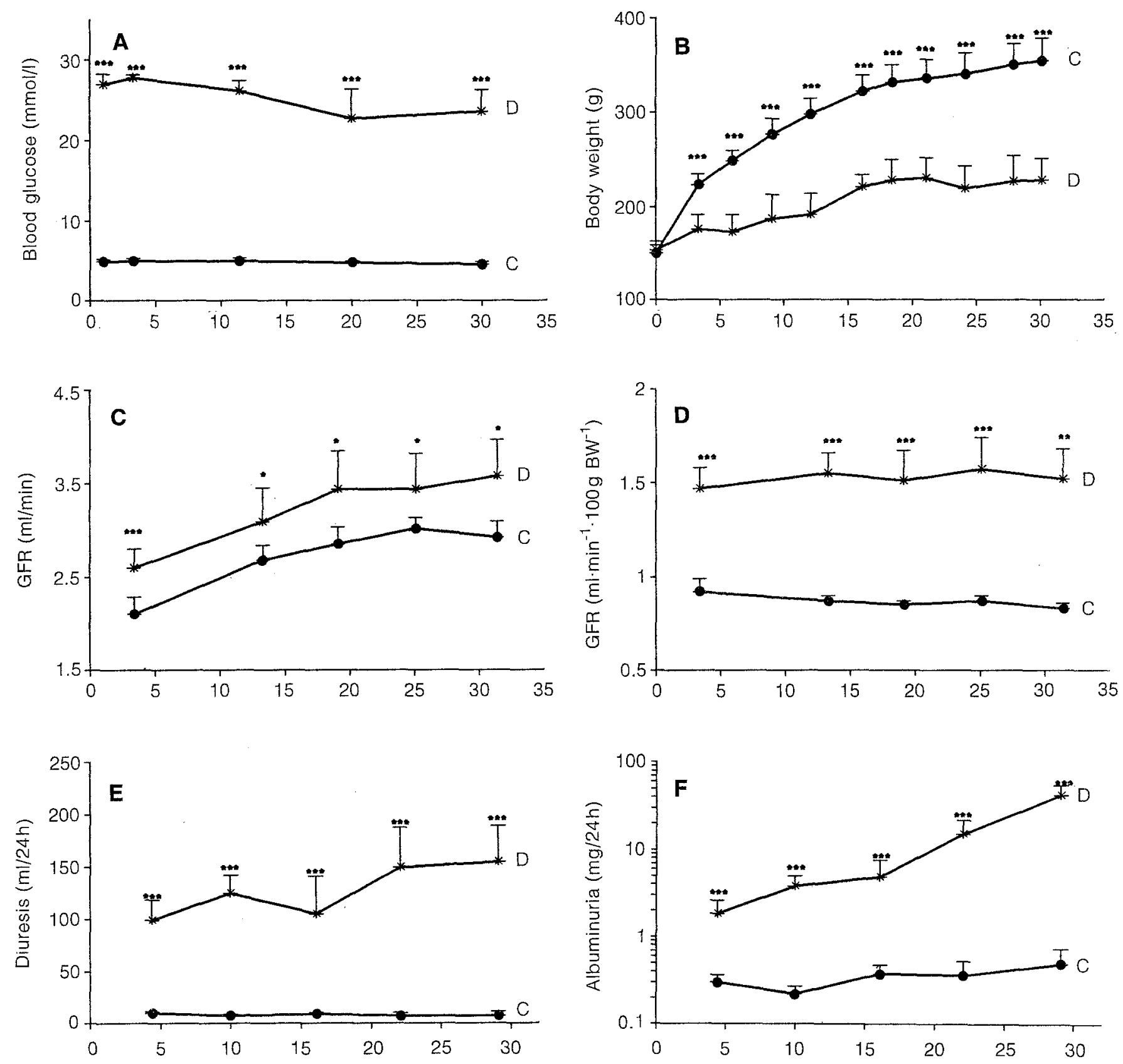

Weeks after diabetes-induction

Fig. 1. (A-F) Longitudinal study during 8 months diabetes. Diabetic $\left(\mathrm{D}^{*}\right)$ and control $\left(\mathrm{C}^{\bullet}\right)$ rats were followed for blood glucose (A), body weight (B), GFR (C), GFR corrected for body

weight (D), diuresis (E) and albuminuria (F). Significance of differences between groups $* p<0.05, \quad * * p<0.01$, $* * * * 0.002$

Table 2. Blood glucose, renal haemodynamics and kidney weight after 8 months of diabetes (mean \pm SD)

\begin{tabular}{llll}
\hline & Diabetic rats $(n=13)$ & Control rats $(n=5)$ & $p$-value \\
\hline Blood glucose just before clearance $(\mathrm{mmol} / \mathrm{l})$ & $23.6 \pm 0.23$ & $4.6 \pm 0.3$ & $<0.002$ \\
GFR $(\mathrm{ml} / \mathrm{min})$ & $4.16 \pm 0.81$ & $3.06 \pm 0.40$ & $<.01$ \\
GFR/BW $(\mathrm{ml} / \mathrm{min} \times 100 \mathrm{~g} \mathrm{BW})$ & $1.69 \pm 0.24$ & $0.84 \pm 0.06$ & $<.02 \pm 1.28$ \\
ERPF $(\mathrm{ml} / \mathrm{min})$ & $9.72 \pm 1.34$ & $2.17 \pm 0.24$ & $<0.05$ \\
ERPF $/ \mathrm{BW}(\mathrm{ml} / \mathrm{min} \times 100 \mathrm{~g} \mathrm{BW})$ & $3.99 \pm 0.58$ & $0.39 \pm 0.04$ & $\mathrm{~N}$ \\
Filtration fraction & $0.43 \pm 0.08$ & $145 \pm 8$ & $\mathrm{NS}$ \\
Mean arterial pressure $(\mathrm{mm} \mathrm{Hg})$ & $146 \pm 11$ & $2.22 \pm 0.18$ & $<0.002$ \\
Wet weight kidneys $(\mathrm{g})$ & $3.26 \pm 0.23$ & $0.61 \pm 0.02$ & $<0.002$ \\
Wet weight kidneys/BW $(\mathrm{g} / 100 \mathrm{~g} \mathrm{BW})$ & $1.34 \pm 0.11$ & & \\
\hline
\end{tabular}




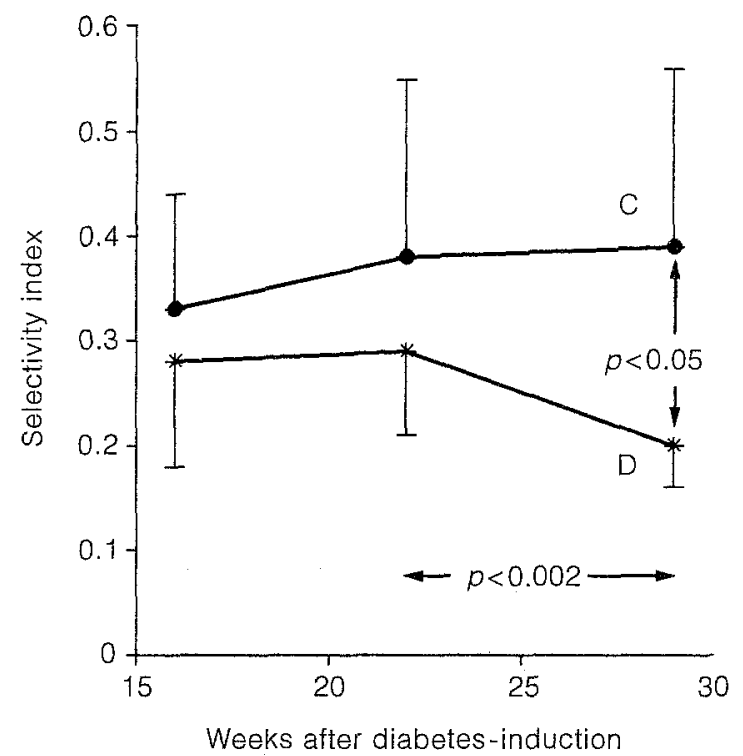

Fig. 2. Selectivity index (clearance IgG/clearance of albumin) of the proteinuria was calculated 16, 22 and 29 weeks after diabetes induction. No alterations were observed in the control rats (C--); however a significant decrease was found in the diabetic rats $\left(D_{-*-}\right)$, suggesting loss of negative charge from the glomerular capillary wall

neys of the diabetic rats are significantly enlarged as demonstrated by the difference in wet weight of the kidneys, which is even more evident after correction for $\mathrm{BW}$.

Histology. Light microscopy demonstrated a moderate increase of the mesangial matrix in the glomeruli of most diabetic rats (Fig. $3 \mathrm{~A}$ and $\mathrm{B}$ ). In addition, in all diabetic animals focal, segmental hyalinosis, sclerosis and adhesions to the Bowman's capsule were
J. van den Born et al.: Heparan sulphate in experimental diabetes

observed. Hyalinosis was predominantly subendothelial and often found to be associated with splitting of the GBM. In all diabetic rats, a focal mesangial deposition of foamy material was observed. None of these alterations were seen in the control animals. Direct immunofluorescence showed positivity for $\mathrm{Ig}$ of the hyaline deposits, but almost no C3 and fibrin (not shown). Measurements of the GBM width on electron microscopy demonstrated a thickened GBM in the diabetic rats (D: $281 \pm 32$ vs C: $239 \pm 14 \mathrm{~nm}$; $p<0.05$ ). To evaluate semiquantitatively possible alterations in glomerular extracellular matrix components, kidney cryostat sections were stained for the core protein of HSPG and HS, collagen III and IV, and laminin. Representative examples are shown in Figures 4 and 5. In control rats the glomerular staining for laminin is weak compared to tubular basement membrane staining, and is predominantly located in mesangial regions (Fig. 4A). However, in diabetic rats we observed a clear increase of the glomerular staining for laminin, not only in the mesangium, but also very prominently along the GBM (Fig.4B). With the antibodies against collagen IV $(\alpha 1, \alpha 2)$ used in this study we observed predominantly a mesangial staining pattern in normal rats (Fig. 4C), that increased slightly in diabetic rats, not only in the mesangium but also in the GBM (Fig.4D). Collagen III had a very low expression in the mesangium of control rats (Fig.4E), which increased in diabetic rats both in the mesangium and the GBM (Fig.4F). The core protein of HSPG is abundantly present in the GBM and to a lesser extent in the tubular basement membrane as described [8]. No differences could be observed between control (Fig. $5 \mathrm{~A}$ ) and diabetic rats (Fig. 5 B). MAb JM-403 directed against the HS-side chains of HSPG showed an intense linear staining of
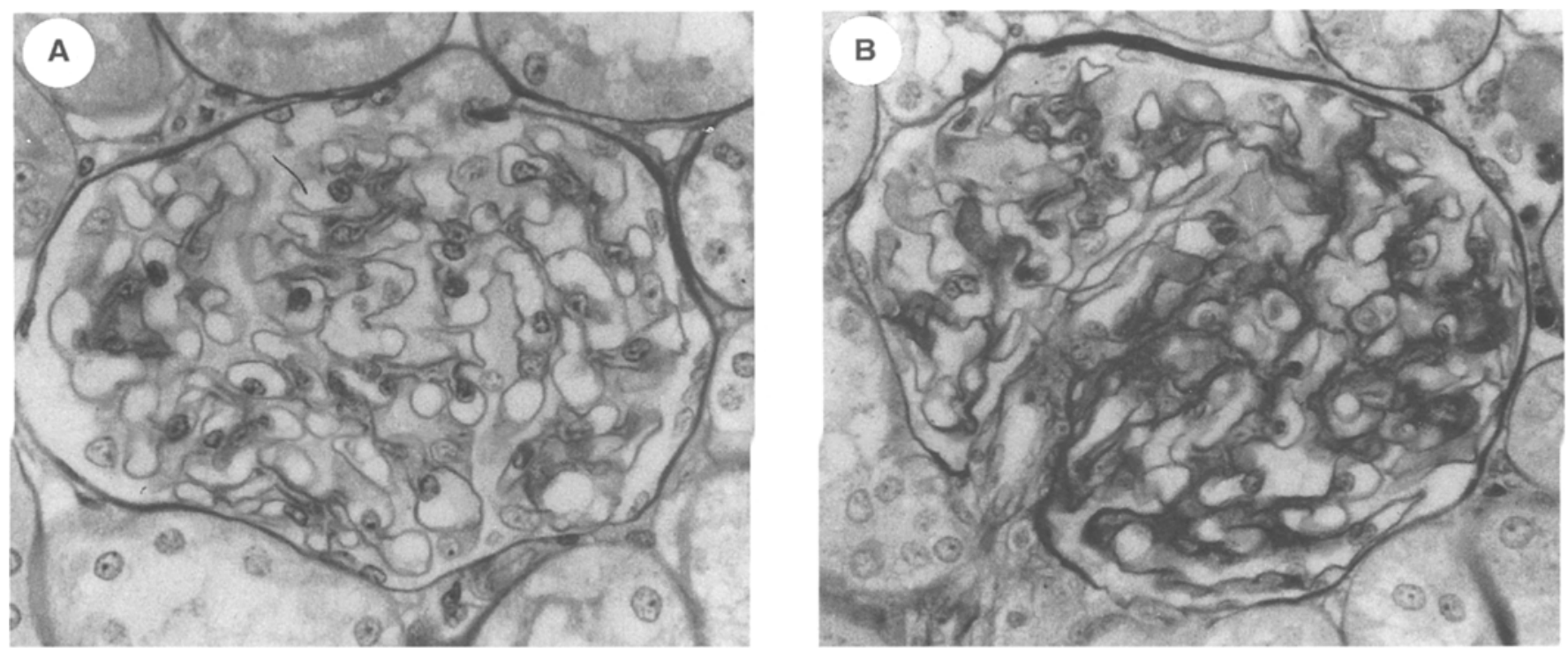

Fig. 3. (A, B) Light microscopy of renal tissue. PAS staining of glomeruli from a control (A) and a diabetic (B) rat. Note the diabetes-induced increase in mesangial matrix. Magnification $\times 540$ 

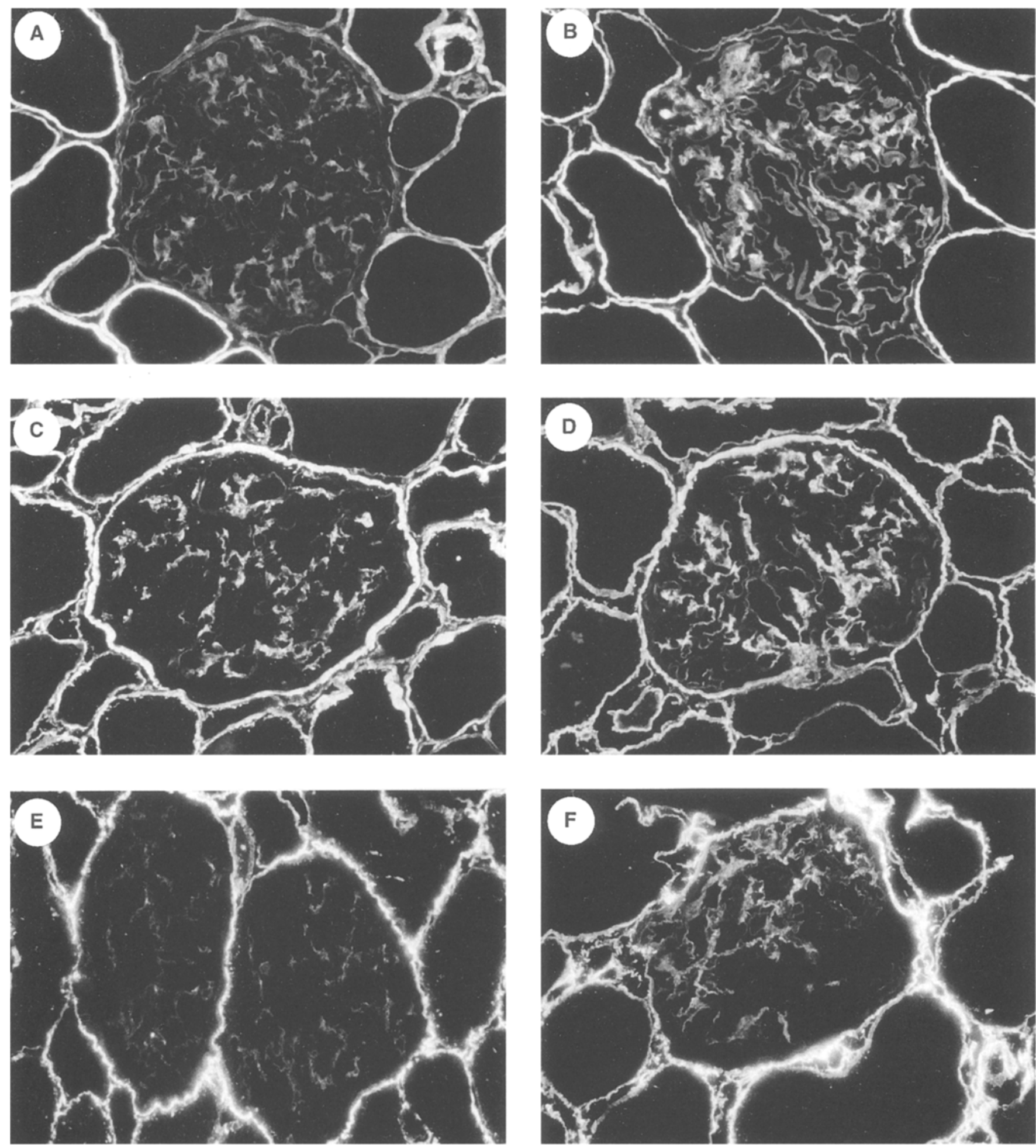

Fig. 4. (A-F) Glomerular staining of laminin, and collagen IV and III by indirect IF. Cryostat sections of control rats (A, C and $\mathbf{E})$ and diabetic rats $(\mathbf{B}, \mathbf{D}$ and $\mathbf{F})$ were stained for laminin

the GBM and of the basement membranes around vascular smooth muscle cells and a weak staining of the tubular basement membranes as previously reported [8]. No differences could be observed between control (Fig.5C) and diabetic rats (Fig.5D).
(A and B), collagen IV (C and D), and collagen III ( $\mathbf{E}$ and $\mathbf{F}$ ). Note the increase of laminin and both collagens in the mesangium and the GBM in the diabetic rats. Magnification $\times 350$

These semiquantitative immunofluorescence results demonstrate an increase of the extracellular matrix proteins laminin, collagen III and IV in the mesangium and the GBM, without obvious alterations in HSPG core protein and HS staining. 

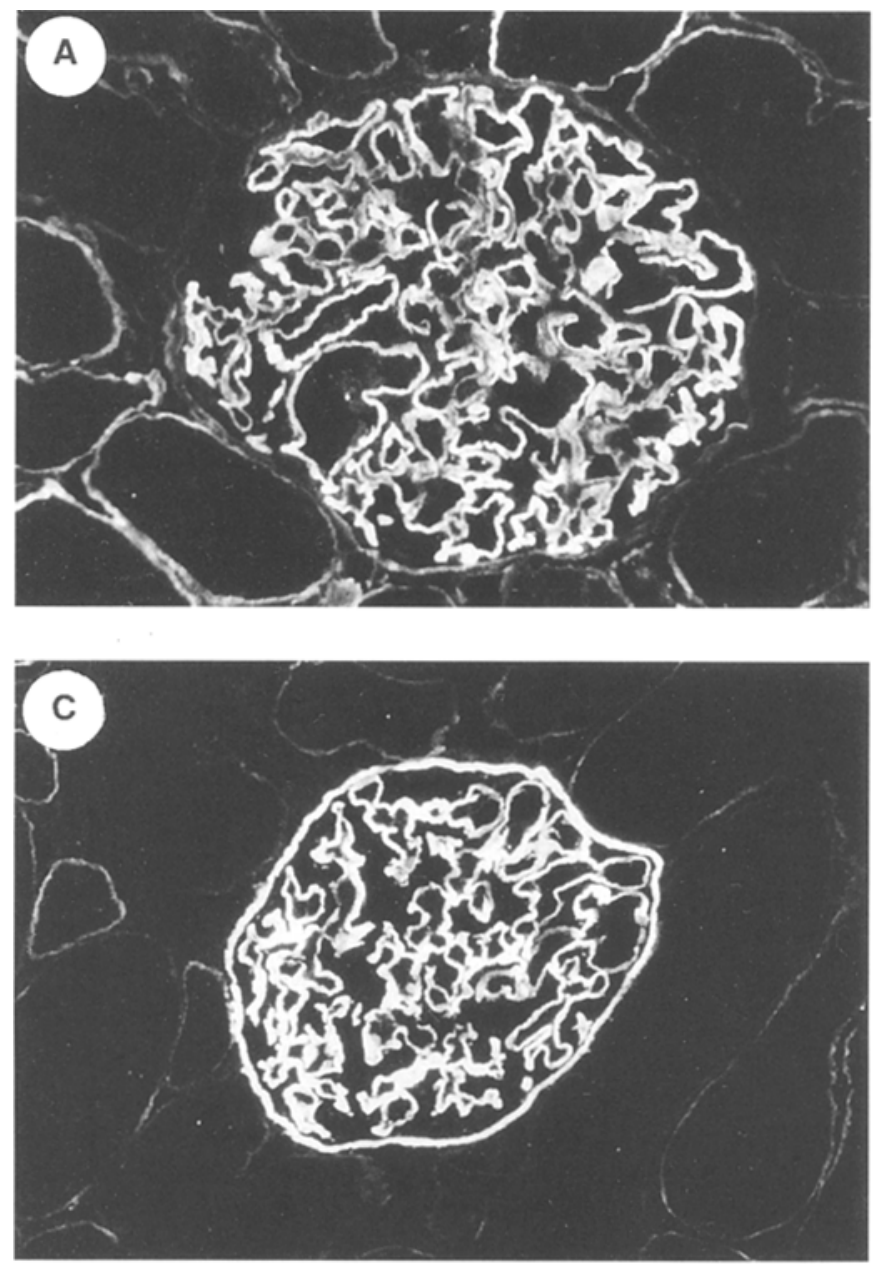

Fig.5. (A-D) Glomerular staining of HSPG-core protein and $\mathrm{HS}$ by indirect immunofluorescence. Cryostat sections of control rats $(\mathbf{A}$ and $\mathbf{C})$ and diabetic rats $(\mathbf{B}$ and $\mathbf{D})$ were stained for HSPG-core protein (A and $\mathbf{B})$ and HS (C and D). No alte-

Glomerular HS and 4-hydroxyproline determination. In order to measure GBM HS content more precisely, glomerular guanidine extracts of individual rats were analysed with an inhibition-ELISA using antiHS mAb JM-403. HS content was calculated based on the standard HS curve of the same microtitre plate. Figure 6 shows a typical standard HS curve and one example of a glomerular extract. Extraction buffer alone in the same dilution range did not inhibit at all. The guanidine extraction liberates $85 \%$ of the total glomerular HS content, since alkaline borohydride treatment of the pellet, obtained after guanidine extraction, contained $15 \%$ of the HS content present in whole glomeruli treated with alkaline borohydride. The glomerular pellet obtained after guanidine extraction was used to measure glomerular 4-hydroxyproline content. In pilot experiments, we found that $93 \%$ of the total glomerular hydroxyproline is still present in the pellet, indicating that guanidine treatment of glomeruli is very ineffective in solubilizing collagens, as was also indicated by oth-
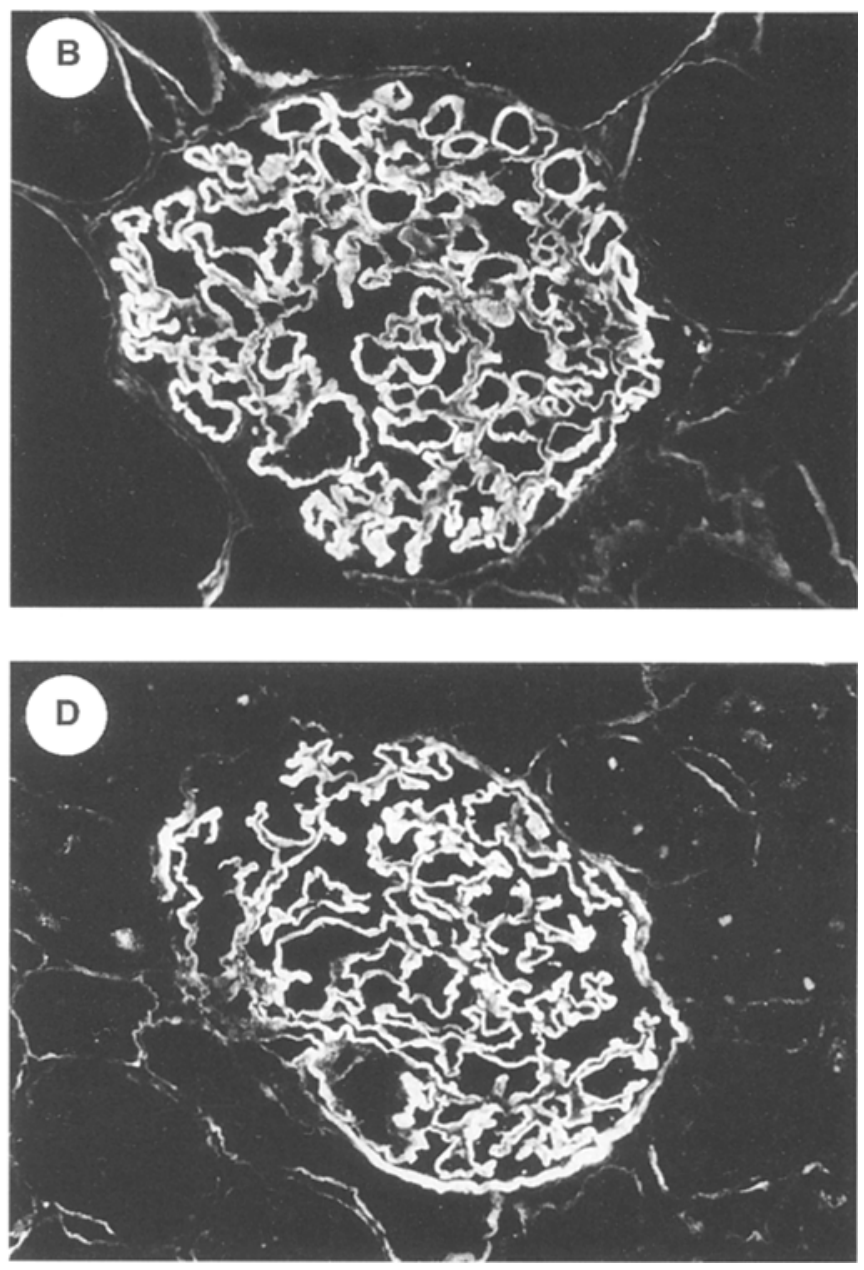

rations were observed in GBM staining for the HSPG-core protein and HS. Sometimes HS staining of Bowman's capsule was interrupted in diabetic rats $(\mathbf{D})$. Magnification $\times 350$

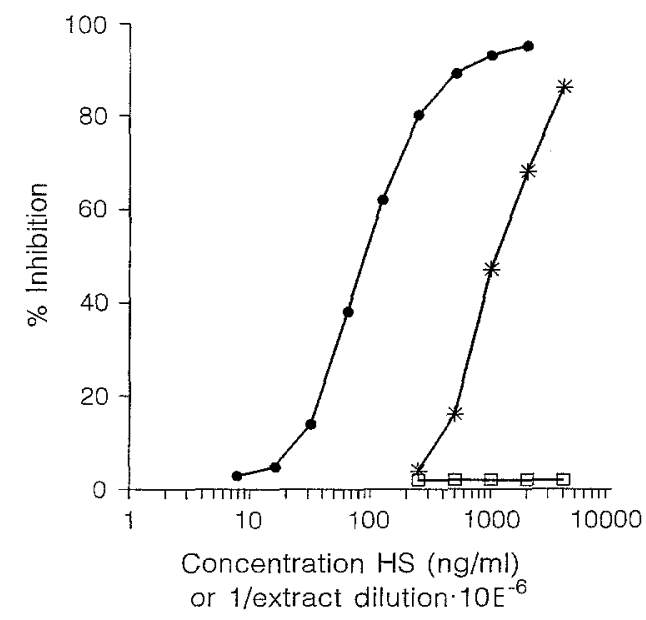

Fig. 6. Example of HS quantitation in the inhibition ELISA. Measurement of a representative glomerular guanidine extract, diluted $250-4000$ times $(-*-)$, and extraction buffer in the same dilution range $(-\square-)$. GBM HS content was calculated based on the HS standard in the same ELISA plate (- - ). The sensitivity of the assay is around $25 \mathrm{ng} \mathrm{HS} / \mathrm{ml}, 50 \%$ inhibition around $100 \mathrm{ng} \mathrm{HS} / \mathrm{ml}$ 
ers [16]. No differences in the extraction efficiency of HS and 4-hydroxyproline were found between control and diabetic rats (data not shown). Figure 7 shows for control $(n=5)$ and diabetic $(n=13)$ rats the glomerular HS content (A), 4-hydroxyproline content (B), and the HS/4-hydroxyproline ratio (C). The results showed no alterations in absolute HS content (median (range) D: 314 (152-941) vs C: 262 (244-467) ng HS/mg glomeruli). Expression of the glomerular HS content per 1000 glomeruli or per mg glomerular protein did not demonstrate significant differences between diabetic and control rats (not shown). The glomerular hydroxyproline content was significantly higher in diabetic rats (median (range) D: 1665 (712-2014) vs C: 672 (515-1208) ng hydroxyproline/mg glomerulus, $p<0.01$ ) and consequently the HS/4-hydroxyproline ratio was significantly decreased in diabetic rats (median (range) D: 0.21 $(0.14-1.16)$ vs $\mathrm{C}: 0.39(0.30-0.47), p<0.05)$.

\section{Discussion}

In this study we analysed whether albuminuria and renal hyperfiltration in STZ-diabetic rats are associated with changes in the amount of GBM HS. For this purpose, we developed a new immunochemical HS-assay, using mAb JM-403 directed against GBM HS [8]. This assay offers several advantages compared to the classic biochemical HS determinations as outlined previously.

From the experiments with different degrees of glycaemic control it becomes clear that high insulin treatment leading to blood glucose levels between 5 and $10 \mathrm{mmol} / 1$ prevents the development of albuminuria and an increased GFR. Treatment with low doses of insulin leading to blood glucose levels between 20 and $25 \mathrm{mmol} / \mathrm{l}$ is associated with a clearly elevated GFR and a pronounced albuminuria, in contrast to untreated diabetic animals. In this group the GFR was not elevated and the observed albuminuria was clearly lower. This suggests that an increased GFR is a major determinant for the glomerular injury as previously suggested [36]. It also confirms that hyperfiltration is not only the direct consequence of a high blood glucose [35, 47]. Also, Allen and co-workers [48] found that the GFR in untreated STZ-rats was nearly normal, while it was clearly elevated in animals treated with moderate doses of insulin. Based on these results, we performed a longitudinal study for 8 months, in which we treated the diabetic rats with low doses of insulin and measured the GFR repeatedly in the same animals. From both the GFR measurements during the study period as well as from the more precise measurements at 8 months it becomes clear that this parameter increases quickly after diabetes induction and remains elevated during the whole observation period. The observed altera-
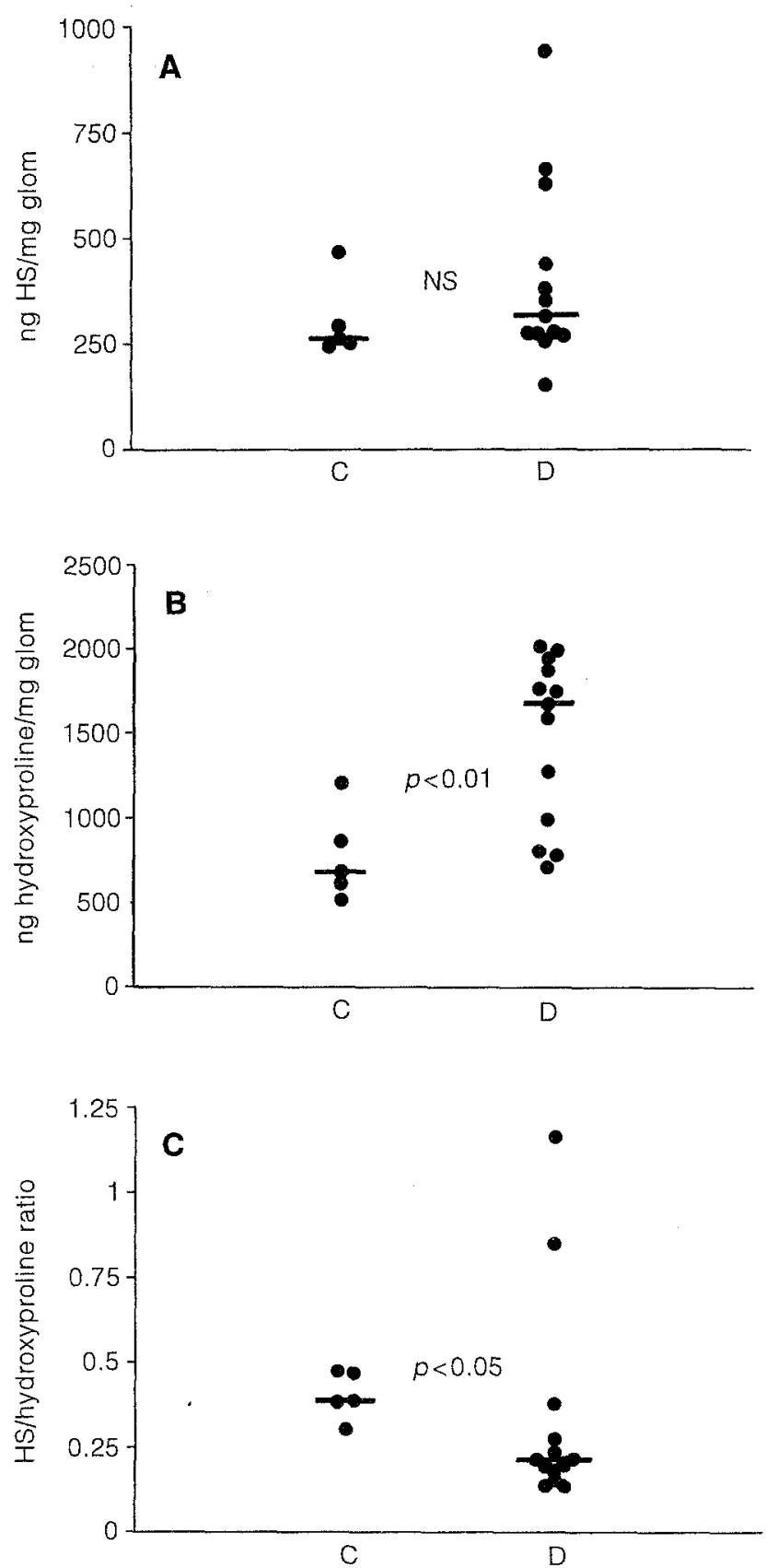

Fig. 7. (A-C) Measurements of glomerular HS, 4-hydroxyproline and their ratio. HS content (A), 4-hydroxyproline content (B) and the HS/4-hydroxyproline ratio (C) were determined in glomeruli from individual rats. Median values are indicated by horizontal bars, significance between control (C) and diabetic (D) rats is also indicated

tions in renal haemodynamics in the diabetic rats were not related to changes in systemic haemodynamics, since these were not different from control animals (Table 2).

As stated before, GBM HS is thought to play an important role in maintaining the charge-selective properties of the glomerular capillary wall, since its removal or blocking leads to albuminuria. Several observations have suggested that a decrease of GBM HS is responsible for the progressive albuminuria in 
diabetes. However, in our study we found that the absolute GBM HS content is not decreased in glomeruli of diabetic rats, but that other extracellular matrix components were increased. This was concluded from a number of observations: an increase in mesangium and GBM of laminin, and collagen III and IV in the immunofluorescence experiments; a significant increase in glomerular 4-hydroxyproline content; a mesangial enlargement on light microscopy; and a significant GBM thickening on electron microscopy. These findings strongly suggest a relative HS decrease, mainly due to an increase of other extracellular matrix constituents as expressed by a significant decrease of the glomerular HS/4-hydroxyproline ratio in diabetic rats. This relative decrease of HS may lead to a dilution of the negative charges within the GBM, leading to an enhanced protein permeability through the GBM. Our observation of a relative HS decrease is in accordance with findings of other investigators in the same model $[27,49]$. Also in a diabetic model in the mouse [50] and in other models of glomerular injury, a generalized upregulation of extracellular matrix constituents was not paralleled by an upregulation of basement membrane HSPG (reviewed by Kopp et al. [51]). Transforming growth factor- $\beta 1$ is thought to play a leading role in this process [52, 53]. In vitro studies using rat glomerular visceral epithelial cells in culture demonstrated a major role for transforming growth factor- $\beta 1$ in upregulating the production of extracellular matrix including fibronectin, collagen IV and dermatan sulphate proteoglycan (biglycan), without influencing HSPG production [54]. The reduced HS and HSPG concentrations found in human diabetic GBM, expressed as hexuronic acid residues/1000 amino acid residues [15] or $\mu \mathrm{g} \mathrm{HSPG} / \mathrm{mg}$ GBM [16] or as the number of antiHSPG immunogold particles/ $\mu \mathrm{m}^{2}$ GBM [17] may also be explained by overproduction of other extracellular matrix constituents. A relative HS decrease will result in a diminished charge density within the GBM and may explain the development of a progressive albuminuria in our rats and the declining $\mathrm{IgG} / \mathrm{al}-$ bumin selectivity index. This latter finding is in agreement with observations in human incipient diabetic nephropathy, showing a decline in $\mathrm{IgG} / \mathrm{IgG} 4$ $[12,13]$ or albumin/glycated albumin [14] selectivity indices.

The HS and 4-hydroxyproline content of the GBM in diabetic animals was compared to age-matched control animals. However, due to the diabetic state the diabetic animals had a lower BW than the control animals. This raises the question of whether this lower BW may have influenced the composition of the GBM. To rule out this possibility we should have compared our diabetic animals with weight-matched controls. To this end we should have taken 3-monthold control animals. Based on data in the literature [55] it is obvious that the amount of GBM HS de- creases and of collagen, increases with age. Therefore, it can be expected that weight-matched younger control animals would have had even a higher HS/ 4-hydroxyproline ratio. We therefore can exclude that the observed difference in HS/4-hydroxyproline ratios between diabetic and age-matched control animals is influenced by the lower BW of the diabetic animals.

Another possibility, that we cannot rule out, is that the HS present in the GBM of the STZ-rats is undersulphated. The HS-charge is mainly dependent on the extent of sulphation, which occurs in the Golgiapparatus of the cell and is determined by the key enzyme glucosaminyl N-deacetylase [56]. A decreased activity of this enzyme has been found in STZ-diabetic rats [57-59]. Undersulphation of HS both from the GBM [28] as well as from other tissues $[60,61]$ in STZ rats has been reported. Very recently, it has been shown that culture of mesangial cells on non-enzymatic glycated mesangial matrix or prolonged exposure to elevated glucose leads to the production of undersulphated proteoglycans [62]. Further structural analysis of GBM HS isolated from diabetic and control rats is needed to elucidate this point, and we are currently adressing this issue.

Besides changes in the density or structure of HS in the GBM other mechanisms may also play a role in the disturbance of the filtration barrier of the GBM in diabetic nephropathy, like the binding and cross-linking of non-enzymatically glycated plasma proteins to the GBM. Also basement membrane constituents themselves can become non-enzymatically glycated, thereby influencing GBM integrity [63-68].

Our results, showing no decrease of HS staining in the GBM of STZ-diabetic rats seem to be in contrast to our previous findings in human diabetic kidneys $[19,20]$, in which GBM HS staining was significantly diminished, whereas the GBM HSPG-core protein staining was unaltered. In addition, we and others $[18,20]$ could demonstrate a correlation between GBM HS staining and fractional urinary protein excretion in human diabetic nephropathy. A major difference between the studies in experimental animals and in humans was the duration of the diabetes and the severity of the diabetic nephropathy. Since the changes on light microscopy in our rats were less severe than those observed in patients, a decrease of the HS-epitope recognized by our mAb JM-403 may occur predominantly in more advanced stages of diabetic nephropathy. An alternative explanation could be that the diabetic nephropathy in the STZ-diabetes model is different in this respect to human diabetic nephropathy.

In summary, in this study we demonstrate that in hyperglycaemic insulin-treated STZ-diabetic rats, glomerular hyperfiltration and a progressive, selective proteinuria are associated with a relative decrease of GBM HS. 
Acknowledgements. This study was supported by a grant (NSN 90.1040) from the Dutch Kidney Foundation. The laboratories participate in a concerted action "Alterations in extracellular matrix components in diabetic nephropathy and other glomerular diseases" which is financially supported by the EC within the Biomed I program (BMH1-CT92-1766). The authors thank J. Koedam and G. Grutters of the Central Animal Laboratory for their assistance in the animal experiments. H. Dijkman and J.van der Laak (Department of Pathology, University of Nijmegen) are gratefully acknowledged for assistance in the electron microscopy studies, L. Burgers (Department of Pathology, University of Nijmegen) for expert assistance in the light microscopy, and B.de Man (Department of Surgery, University of Nijmegen) for the 4-hydroxyproline measurements.

\section{References}

1. Kanwar YS, Liu ZZ, Kashihara N, Wallner EI (1991) Current status of the structural and functional basis of glomerular filtration and proteinuria. Semin Nephrol 11:390-413

2. Farquhar MG (1991) The glomerular basement membrane. A selective macromolecular filter. In: Hay ED (ed) Cell biology of extracellular matrix. Plenum Press, New York pp 365-418

3. Rosenzweig LJ, Kanwar YS (1982) Removal of sulfated (heparan sulfate) or nonsulfated (hyaluronic acid) glycosaminoglycans results in increased permeability of the glomerular basement membrane to ${ }^{125}$-I-bovine serum albumin. Lab Invest 47: 177-184

4. Vehaskari VM, Root ER, Germuth FG, Robson AM (1982) Glomerular charge and urinary protein excretion. Effects of systemic and intrarenal polycation infusion in the rat. Kidney Int 22: 127-135

5. Hunsicker LG, Shearer TP, Shaffer SJ (1981) Acute reversible proteinuria induced by infusion of the polycation hexadimethrine. Kidney Int 20: 7-17

6. Assel E, Neumann K-H, Schurek H-J, Sonnenburg C, Stolte H (1984) Glomerular albumin leakage and morphology after neutralization of polyanions; I. Albumin clearance and sieving coefficient in the isolated perfused rat kidney. $\mathrm{Re}$ nal Physiol (Basel) 7: 357-364

7. Sonnenburg-Hatzopoulos C, Assel E, Schurek HJ, Stolte H (1984) Glomerular albumin leakage and morphology after neutralization of polyanions; II. Discrepancy of protamine induced albuminuria and fine structure of the glomerular filtration barrier. J Submicrosc Cytol 16: 741-751

8. Born van den J, Heuvel van den LPWJ, Bakker MAH, Veerkamp JH, Assmann KJM, Berden JHM (1992) A monoclonal antibody against GBM heparan sulfate induces an acute selective proteinuria in rats. Kidney Int 41: 115-123

9. Mogensen CE (1984) Microalbuminuria predicts clinical proteinuria and early mortality in maturity-onset diabetes. N Eng J Med 310: 356-360

10. Viberti GC, Hill RD, Jarrett RJ, Argyropoulos A, Mahmud U, Keen H (1982) Microalbuminuria as a predictor of clinical nephropathy in insulin-dependent diabetes mellitus. Lancet I: $1430-1432$

11. Deckert T, Feldt-Rasmussen B, Djurup R, Deckert $M$ (1988) Glomerular size and charge selectivity in insulin-dependent diabetes mellitus. Kidney Int 33: 100-106

12. Deckert T, Kofoed-Enevoldsen A, Vidal P, Norgaard K, Andreasen HB, Feldt-Rasmussen B (1993) Size- and charge selectivity of glomerular filtration in type 1 (insulindependent) diabetic patients with and without albuminuria. Diabetologia 36: $244-251$
13. Bangstad H-J, Kofoed-Enevoldsen A, Dahl-Jorgensen K, Hanssen KF (1992) Glomerular charge selectivity and the influence of improved blood glucose control in type 1 (insulin-dependent) diabetic patients with microalbuminuria. Diabetologia 35: 1165-1169

14. Kverneland A, Feldt-Rasmussen B, Vidal P et al. (1986) Evidence of changes in renal charge selectivity in patients with type 1 (insulin-dependent) diabetes mellitus. Diabetologia 29: 634-639

15. Parthasarathy N, Spiro RG (1982) Effect of diabetes on the glycosaminoglycan component of the human glomerular basement membrane. Diabetes 31: 738-741

16. Shimomura H, Spiro RG (1987) Studies on macromolecular components of human glomerular basement membrane and alterations in diabetes; decreased levels of heparan sulfate proteoglycan and laminin. Diabetes 36: 374-381

17. Makino H, Yamasaki Y, Haramoto T et al. (1993) Ultrastructural changes of extracellular matrices in diabetic nephropathy revealed by high resolution scanning and immunoelectron microscopy. Lab Invest 68: 45-55

18. Vernier RL, Steffes MW, Sisson-Ross S, Mauer M (1992) Heparan sulfate proteoglycan in the glomerular basement membrane in type I diabetes mellitus. Kidney Int 41: 10701080

19. Born van den J, Heuvel van den LPWJ, Bakker MAH et al. (1993) Distribution of GBM heparan sulfate proteoglycan core protein and side chains in human glomerular diseases. Kidney Int 43: 454-463

20. Tamsma JT, Born van den J, Bruijn JA et al. (1994) Expression of glomerular extracellular matrix components in human diabetic nephropathy: decrease of heparan sulphate in the glomerular basement membrane. Diabetologia 37:313-320

21. Nerlich A, Schleicher E (1991) Immunohistochemical localization of extracellular matrix components in human diabetic glomerular lesions. Am J Pathol 139: 889-899

22. Makino H, Ikeda S, Haramoto T, Ota Z (1992) Heparan sulfate proteoglycans are lost in patients with diabetic nephropathy. Nephron 61: 415-421

23. Saraswathi S, Vasan NS (1983) Alterations in the rat renal glycosaminoglycans in streptozotocin-induced diabetes. Biochim Biophys Acta 755: 237-243

24. Wu V-Y, Wilson B, Cohen MP (1987) Disturbances in glomerular basement membrane glycosaminoglycans in experimental diabetes. Diabetes 369: 679-683

25. Reddi AS (1991) Prevention of albuminuria by captopril in diabetic rats. Gen Pharmac 22: 323-328

26. Reddi AS, Ramamurthi R, Miller M, Dhuper S, Lasker N (1991) Enalapril improves albuminuria by preventing glomerular loss of heparan sulfate in diabetic rats. Biochem Med Metab Biol 45: 119-131

27. Templeton DM (1989) Retention of glomerular basement membrane-proteoglycans accompanying loss of anionic site staining in experimental diabetes. Lab Invest 61: 202-211

28. Cohen MP, Klepser H, Wu V-Y (1988) Undersulfation of glomerular basement membrane heparan sulfate in experimental diabetes and lack of correction with aldolase reductase inhibition. Diabetes 37: 1324-1327

29. Cohen MG, Surma ML (1984) Effect of diabetes on in vivo metabolism of $\left[{ }^{35} \mathrm{~S}\right]$-labeled glomerular basement membrane. Diabetes 33: 8-12

30. Klein DJ, Brown DM, Oegema TR (1986) Glomerular proteoglycans in diabetes. Partial structural characterization and metabolism of de novo synthesized heparan-35\$04 and dermatan-35S04 proteoglycans in streptozotocin-induced diabetic rats. Diabetes 35: 1130-1142

31. Warren J, Mason RM (1992) Steady state measurement of glomerular proteoglycan synthesis in streptozotocin-induced diabetes. Biochem Soc Trans 20:97S 
32. Kanwar YS, Rosenzweig LJ, Linker A, Jakubowski ML (1983) Decreased de novo synthesis of glomerular proteoglycans in diabetes: biochemical and autoradiographic evidence. Proc Natl Acad Sci USA 80: 2272-2275

33. Cohen MP, Surma ML (1981) ${ }^{35}$ S-sulfate incorporation into glomerular basement membrane glycosaminoglycans is decreased in experimental diabetes. J Lab. Clin Med 98: 715722

34. Beavan LA, Davies M, Mason RM (1988) Renal glomerular proteoglycans; an investigation of their synthesis in vivo using a technique for fixation in situ. Biochem J 251: 411-418

35. O'Donnell MP, Kasiske BL, Keane WF (1988) Glomerular hemodynamic and structural alterations in experimental diabetes mellitus. FASEB J 2: 2339

36. Zatz R, Meyer TW, Rennke HG, Brenner BM (1985) Predominance of hemodynamic rather than metabolic factors in the pathogenesis of diabetic glomerulopathy. Proc Natl Acad Sci USA 82: 5963-5967

37. Zatz R, Dunn BR, Meyer TW, Anderson S, Rennke HG, Brenner BM (1986) Prevention of diabetic glomerulopathy by pharmacological amelioration of glomerular capillary hypertension. J Clin Invest 77: 1925-1930

38. Anderson S, Rennke HG, Garcia DL, Brenner BM, Riley SL, Sandstrom DJ (1989) Short and long term effects of antihypertensive therapy in the diabetic rat. Kidney Int 36: $526-536$

39. Laurell CB (1966) Quantitative estimation of proteins of electrophoresis in agarose gel containing antibodies. Anal Biochem 15: 45-52

40. Provoost AP, Keijzer de MH, Wolff ED, Molenaar JC (1983) Development of renal function in the rat. The measurements of GFR and ERPF and correlation to body and kidney weight. Renal Physiol 6: 1-9

41. Harvey JN, Jaffa AA, Loadholt CB, Mayfield RK (1988) Measurement of glomerular filtration rate and renal plasma flow in the diabetic rat by the single-injection isotopic technique: effects of altered distribution volumes of $51 \mathrm{Cr}$ EDTA and 125I-hippuran. Diab Res 9: 67-72

42. Lambalgen van AA, Kraats van AA, Bos van den $G C$ et al. (1991) Renal function and metabolism during endotoxemia in rats: role of hypoperfusion. Circ Shock 35: 164-173

43. Passing H, Bablok W (1983) A new biometrical procedure for testing the equality of measurements from two different analytical methods. J Clin Chem Clin Biochem 21: 709-720

44. Heuvel van den LPWJ, Born van den J, Velden van de TJAM et al. (1989) Isolation and partial characterization of heparan sulfate proteoglycan from the human glomerular basement membrane. Biochem J 264: 457-465

45. Meezan E, Hjelle JT, Brendel K, Carlson EC (1975) A simple, versatile, nondisruptive method for the isolation of morphologically and chemically pure basement membranes from several tissues. Life Sci 17: 1721-1732

46. Berg RA (1982) Determination of 3- and 4-hydroxyproline. Meth Enzym 82: 372-398

47. Hostetter TH, Troy JL, Brenner BM (1981) Glomerular hemodynamics in experimental diabetes mellitus. Kidney Int 19: $410-415$

48. Allen TJ, Cooper ME, O'Brien RC, Bach LA, Jackson B, Jerums $G(1990)$ Glomerular filtration rate in streptozotocin-induced diabetic rats. Role of exchangeable sodium, vasoactive hormones, and insulin therapy. Diabetes 39: 1182-1190

49. Fukui M, Nakamura T, Ebihara I, Shirato I, Tomino Y, Koide H (1992) ECM gene expression and its modulation by insulin in diabetic rats. Diabetes 41: 1520-1527

50. Ledbetter S, Copeland EJ, Noonan D, Vogeli G, Hassell JR (1990) Altered steady-state mRNA levels of basement membrane proteins in diabetic mouse kidneys and thromboxane synthase inhibition. Diabetes 39: 196-203

51. Kopp JB, Bruggeman LA, Klotman PE (1993) Extracellular matrix gene expression in experimental glomerulonephritis. Curr Opin Nephrol Hypertens 2: 609-617

52. Border WA, Noble NA (1993) Cytokines in kidney disease: the role of transforming growth factor- $\mathrm{B}$. Am $\mathrm{J}$ Kidney Dis 22: $105-113$

53. Yamamoto T, Nakamura T, Noble NA, Ruoslahti E, Border WA (1993) Expression of transforming growth factor-B is elevated in human and experimental diabetic nephropathy. Proc Natl Acad Sci USA 90: 1814-1818

54. Nakamura T, Miller D, Ruoslahti E, Border WA (1992) Production of extracellular matrix by glomerular epithelial cells is regulated by transforming growth factor-B 1 . Kidney Int 41: $1213-1221$

55. Veerkamp JH (1987) Age-related structural changes in glomerular and tubular basement membranes. In: Price RG, Hudson BG (eds) Renal basement membranes in health and disease. Academic Press, London pp 135-146

56. Lindahl U, Kusche M, Lidholt K, Oscarsson L-G (1989) Biosynthesis of heparin and heparan sulfate. Ann NY Acad Sci 556: $36-50$

57. Unger E, Pettersson I, Eriksson UJ, Lindahl U, Kjellén L (1991) Decreased activity of the heparan sulfate-modifying enzyme glucosaminyl $\mathrm{N}$-deacetylase in hepatocytes from streptozotocin-diabetic rats. J Biol Chem 266-8671-8674

58. Kofoed-Enevoldsen A (1992) Inhibition of glomerular glucosaminyl $\mathrm{N}$-deacetylase in diabetic rats. Kidney Int 41 : $763-767$

59. Kofoed-Enevoldsen A, Noonan D, Deckert T (1993) Diabetes mellitus induced inhibition of glucosaminyl N-deacetylase: effect of short-term blood glucose control in diabetic rats. Diabetologia 36: 310-315

60. Levy P, Picard J, Bruel A (1984) Evidence for diabetes-induced alterations in the sulfation of heparan sulfate intestinal epithelial cells. Life Sci 35: 2613-2620

61. Kjellén L, Bielefeld D, Höök M (1983) Reduced sulfation of liver heparan sulfate in experimentally diabetic rats. Diabetes 32: 337-342

62. Silbiger S, Crowley S, Shan Z, Brownlee M, Santriano J, Schlondorff D (1993) Nonenzymatic glycation of mesangial matrix and prolonged exposure of mesangial matrix to elevated glucose reduces collagen synthesis and proteoglycan charge. Kidney Int 43: 853-864

63. Daniels BS, Hostetter TH, Kren SM (1991) Functional and structural alterations of the glomerular permeability barrier in experimental galactosemia. Kidney Int 39: 1104-1111

64. Daniels BS, Hauser EB (1992) Glycation of albumin, not glomerular basement membrane, alters permeability in an in vitro model. Diabetes 41: 1415-1421

65. Garlick RL, Bunn HF, Spiro RG (1988) Nonenzymatic glycation of basement membranes from human glomeruli and bovine sources. Diabetes 37: 1144-1150

66. Charonis AS, Tsilibary EC (1992) Structural and functional changes of laminin and type IV collagen after nonenzymatic glycation. Diabetes 41: 49-51

67. Tarsio JF, Reger LA, Furcht LT (1988) Molecular mechanisms in basement membrane complications of diabetes. Alterations in heparin, laminin, and type IV collagen association. Diabetes 37: 532-539

68. Tarsio JF, Wigness B, Rhode TD, Rupp WM, Buchwald H, Furcht LT (1985) Nonenzymatic glycation of fibronectin and alterations in the molecular association of cell matrix and basement membrane components in diabetes mellitus. Diabetes 34: 477-484 